\title{
We May Not "Have It All," But We Can Make It Better through Structural Changes
}

\author{
Carly Benner Zapata, MD, MPH*, Lekshmi Santhosh, MD
}

Department of Medicine, University of California, San Francisco, San Francisco, California.

$\mathrm{n}$ this issue of the Journal of Hospital Medicine, the paper by Gottenborg et al. captures the experiences of female academic hospitalists navigating one of the most significant transitions they will face-becoming new mothers. ${ }^{1}$ This article gives an accessible voice to impersonal statistics about the barriers women physicians encounter within and across specialties in academia. The challenges and anecdotes shared by the study participants were eminently relatable and captured the all-too-familiar circumstances most of us with children have faced in our careers as physician mothers.

\section{STUDY COMMENTARY AND DISCUSSION}

This study uses qualitative research methods to illustrate the hurdles faced by mothers in hospital medicine beyond what is demonstrated by quantitative measures and provides the helpful step of proposing some solutions to the obstacles they have faced. While the sample size was very small, the women interviewed were diverse in their years in practice, geographic distribution, and percent clinical effort, providing evidence that the themes discussed prevail across demographic categories.

The snowball sampling via the Society of Hospital Medicine committees may not have yielded a representative sample of female hospitalists. It seems possible that women who are involved in this type of leadership may be better supported and/ or have different work schedules than their peers who are not in leadership positions. We also wish there had been more emphasis on the systemic and structural factors that can improve the quality of life of physician mothers. These policies include paternity leave and other creative ways of acknowledging the useful skills and experience that motherhood brings to bear on clinical practice, such as increased empathy and compassion, as mentioned by one of the study participants.

Even with the aforementioned limitations, this study is important because it combines authentic quotes from practicing academic hospitalists with concrete and tangible suggestions for structural changes. The most striking element is that the majority of the study participants experienced uncertainty and a lack

*Address for correspondence: Carly Benner Zapata, MD, MPH, Assistant Clinical Professor of Medicine, University of California, San Francisco, 533 Parnassus Ave, Suite 115A, Box 0125, San Francisco, CA, 94143; Telephone: 415-502-2947; Fax: 415-476-4818; E-mail: Carly.zapata@ucsf.edu

Received: October 2, 2018; Accepted: October 3, 2018

๑ 2018 Society of Hospital Medicine DOI 10.12788/jhm.3107 of transparency around parental leave policies. As nearly half of hospitalists are women and $80 \%$ are under age $40,{ }^{2}$ it seems unimaginable that there would not be explicit policies in place for what is a common and largely anticipated life event. Medicine has made great strides toward gender equality, but we are unlikely to ever reach the goal of true parity without openly addressing the disproportionate effect of childbearing and child rearing on women physicians. Standardized, readily available, and equitable parental leave policies (for both birth parents and nonbirth parents) are the first and most critical step.

The absence of standard leave policies naturally puts physician mothers in the position of having to negotiate or "haggle" with various supervisors, the majority of whom are male division chiefs and department chairs, ${ }^{3}$ which places all parties in an uncomfortable position, further reinforcing inequities and sowing discord and resentment. Having formal policies around leave protects not only those who utilize parental leave but also the other members of a hospital medicine practice who take on the workload of the person on leave.

Uncertainty around how to address the increased clinical load and for how long, also creates anxiety among other group members and may lead to feelings of bitterness toward clinicians on leave, further contributing to the negative impact of new parenthood on female hospitalists. We can think of no other medical circumstance in which there is as much advance notice of the need for significant time away from work. Yet pregnancy, which is subject to complications and emergencies just like other medical conditions, is treated with so little concern that one may be asked to arrange for their own coverage during such an emergency, as one study subject reported.

We also empathize with the study participants' reports of feeling that supervisors often mentally discounted their ability to participate in projects on return to work. These pernicious assumptions can compound a cycle of lost productivity, disengagement, and attrition from the workforce.

Female hospitalists returning from leave face additional challenges that place an undue burden on their professional activities, most notably related to breastfeeding. This is particularly relevant in the context of the intensity inherent in practicing hospital medicine, which includes long days of being the primary provider for acutely ill inpatients, as well as long stretches of many consecutive days when it may not be possible to return home before children's bedtime. Even at our own institution, which has been recognized as a "Healthy Mothers Workplace," breastfeeding accommodations are not set up to allow for ongoing clinical activities while taking time to express breastmilk, 
and the clinical schedule does not build in adjustments for this time-consuming and psychologically taxing commitment. Breastfeeding for at least one year is the medical recommendation of the American Academy of Pediatrics in line with a substantial body of evidence. ${ }^{4}$ One quote from the article poignantly notes, "Pumping every 3-4 hours: stopping what you're doing, finding an empty room to pump, finding a place to store your milk, then going back to work, three times per shift, for the next 9 months of your life, was hell." If we cannot enable our own medical providers to follow evidence-based recommendations, how can we possibly expect this of our patients?

\section{CONCLUSIONS}

The notion of women "having it all" is an impossible ideal-both work and life outside of work will inevitably require tradeoffs. However, there is an abundance of evidence and recommendations for concrete steps that can be taken to improve the experience of female physicians who have children. These include formal policies for childbearing and child rearing leave (the American Academy of Pediatrics recommends at least six to nine months ${ }^{5}$ ), convenient space and protected time for pumping milk during the first year, on-site childcare services and back-up child care, and flexible work schedules. ${ }^{6}$ It is time to stop treating childbirth among female physicians like an unexpected inconvenience and acknowledge the undeniable demographics of physicians in hospital medicine and the duty of healthcare systems and hospital medicine leaders to effectively plan for the needs of half of their workforce.

Disclosures: Neither of the authors has any financial conflicts of interest to disclose.

\section{References}

1. Gottenborg E, Maw A, Ngov LK, Burden M, Ponomaryova A, Jones CD. You can't have it all: The experience of academic hospitalists during pregnancy, parental leave, and return to work. J Hosp Med. 2018;13(12):836-839. doi: 10.12788/jhm.3076.

2. Reid MB, Misky GJ, Harrison RA, Sharpe B, Auerbach A, Glasheen JJ. Mentorship, productivity, and promotion among academic hospitalists. J Gen Intern Med. 2012;27(1):23-27. doi: 10.1007/s11606-011-1892-5.

3. Association of American Medical Colleges. The state of women in academic medicine: The pipeline and pathways to leadership, 2015-2016. https://www. aamc.org/members/gwims/statistics/. Accessed October 1, 2018.

4. American Academy of Pediatrics. Breastfeeding and the use of human milk. Pediatrics. 2012;129(3):e827-e841. doi: 10.1542/peds.2011-3552.

5. National Public Radio. A Pediatrician's View of Paid Parental Leave. https:// www.npr.org/sections/health-shots/2016/10/10/497052014/a-pediatriciansview-of-paid-parental-leave. Accessed September 26, 2018.

6. Mangurian C, Linos E, Sarkar U, Rodriguez C, Jagsi R. What's holding women in medicine back from leadership? (2018, June 19). Harvard Business Review. https://hbr.org/2018/06/whats-holding-women-in-medicine-back-fromleadership. Accessed October 1, 2018 